\title{
Impact of Government Policies and International Students on UK University Economic Stability
}

\author{
Timothy $\operatorname{Scott}^{1} \&$ Nathara Mhunpiew ${ }^{1}$ \\ ${ }^{1}$ Graduate School of Human Science, Assumption University, Bangkok, Thailand \\ Correspondence: Timothy Scott, School of Human Science, Assumption University, Bangkok, Thailand. E-mail: \\ timothyrscott@hotmail.com
}

Received: December 12, 2020

Accepted: February 13, $2021 \quad$ Online Published: April 25, 2021

doi:10.5539/ies.v14n5p1

URL: https://doi.org/10.5539/ies.v14n5p1

\begin{abstract}
Numerous UK universities are experiencing financial instability; with an increasingly competitive and maturing market, reliance has grown on international students to offset institutional shortfalls. Dependency on international student tuition revenue has over-exposed the market to dramatic shifts in political policies, both domestic and internationally, that could significantly impact operational success. UK higher education institutions (HEIs) ability to promote their institutions as they are intertwined with the UK government; thus, controversial policies create a backlash, drawing HEIs into disputes as unwanted participants yet recipients of significant economic disruption. Government policies on domestic tuition caps, Brexit, and increasing geopolitical disputes with China have had a considerable impact on institutional operations. This paper recommends HEIs, principally lower-tabled universities, take a more aggressive strategic realignment to best adapt to the marketplace's uncertainty. By reemphasising institutional specialisation, variable tuition rates for under-represented growth markets, financial support for EU students, increased distance education presence, and intense market-wide lobbying of government MPs, this paper seeks to open a discussion on how to identify existing problems and target opportunities for growth. The complexity of market conditions and the decreasing solvency of many institutions will not be solved by a single recommendation or a short-term policy but by a complete realignment and robust industry-wide initiatives. If universities cease operations or collapse under market conditions' financial strain, it will impact the overall market's reputation, reducing UK institutions' overall desirability as a major exporter of education.
\end{abstract}

Keywords: dependency, higher education, international students, reforms, UK government

\section{Introduction}

UK higher educational institutions (HEIs) have long sustained strategic advantage in the educational marketplace, with numerous internationally recognised universities and strong government oversight ensuring quality assurance, top international talent strived to attain acceptance. However, academia has undergone dramatic institutional reconceptualisation over the past 40 years, initially spurred on by the deregulation of international student tuition fees and now by the increasingly competitive global educational marketplace. UK HEIs have had to reshape their organisational paradigms to match the growing realities of modern academia. Domestic market saturation, reduced government subsidies and funding, and dramatically increasing operational costs have necessitated institutions to partake in an enhanced internationalisation approach. Though HEIs have assimilated internationalisation previously into their strategic plans, maintaining networks with other educational organisations and agencies to increase human capital for research and development, the fluctuating educational environment has caused policies to incorporate a spectrum of activities to create a comprehensive global presence.

Tuition market caps on home students in the UK are government-regulated, limiting the maximum amount an institution can charge per year of tuition. The UK government has previously provided funding grants to offset tuitional caps on home students, reducing the economic burden on both student and HEI; however, increasing economic pressures and national budget shortfalls have resulted in significant educational funding cutbacks. Tuition caps promote educational engagement by home students, but the increasing economic pressures to maintain appropriate resources and facilities create an immense strain on institutional capabilities. Choudaha (2017) noted that the lack of pricing control in the domestic market, funding constraints, and market saturation, resulting from policies providing private institutions permission to offer accredited degrees, had increased HEIs pressure on recruiting international students. As government policies do not regulate international student tuitions, 
fees can be multiple times higher than a home student, making international student recruitment a primary objective to meet financial demands (Meur et al., 2014). This fundamental shift in strategic policy at the institutional level has caused most HEIs to an entrepreneurial higher education system (Slaughter \& Cantwell, 2012).

UK public universities are autonomous from the government in designating the institutional mission and strategic objectives (Gaskell, 2015); yet, government policies are profoundly influential on the viability of objectives long-term. While the underlying assumption that governments design, implement and reform policies to ensure strategic positional advantage (Sa \& Sabzalieva, 2017), political bipartisanship often leads to populace strategies that may be counterintuitive and damaging to HEIs operations. The focus on education and, more specifically, international student enrollment in HEIs vary immensely from ruling government groupings. Brexit has been the most documented and concerning policy impacting UK HEIs currently, with the reclassification of EU students for 2021 resulting in students' widespread apprehension about their future in the UK (Rios, 2017). The polarisation of the Brexit platform additionally created a deteriorating social climate that saw increased xenophobic behaviour. Political rhetoric has created an unintended level of anxiety among the international student population that creates questions about their ability to continue with extended studies and the degree to which the UK society will continue to accept them. International government relations additionally affect UK HEI recruitment and retention of international students, as prospective students may be persuaded to seek alternative non-UK HEIs if the relationship between the UK government and a foreign nation deteriorates. Trade disputes and tic-for-tac responses to political gesturing directly affect UK HEIs' ability to promote their institutions as they are intertwined with the government, drawing them into disputes as unwanted participants.

The external factors created by the UK government through policy and international engagement are vital contributors to both HEI growth and instability. UK HEIs must insulate themselves from the volatile political environment by preemptively risk-assessing institutional exposure to sudden international student declines; preparing alternative revenue streams, program adjustments, and institutional cooperatives could reduce the impact of enrollment shortfalls. This paper discusses how government policies directly impact the stability of UK HEIs and their ability to recruit and retain international students. Additionally, it will present recommendations to how UK HEIs can hedge their current exposure and improve long-term stability. In doing so, it hopes to alert institutions and decision-makers that international students are a valuable presence; however, dependency on a single group can be impacted by numerous external factors that could significantly reduce institutional certainty.

\section{Tuition Fees}

Home student tuition fees are government regulated, first enacted in the Teaching and Higher Education Act 1998, to ensure upward mobility and educational opportunities for individuals in the UK. Though this policy intended to improve student enrollment and education levels, its implementation also created hardships on institutions to maintain tuition caps while remaining economically sustainable and competitive. Though subsequent years have seen considerable increases to home tuition limits, institutional expenditure has increased in tandem or faster than tuitional revenue (Hubble \& Bolton, 2018). Government austerity policies in the early 2010s reduced public investment and forced significant constraints on educational funding grants and initiatives; these funding reductions, coupled with decreased domestic enrollment, created a spike in budgetary shortfalls across UK HEIs. Home student tuition caps have increased over the past two decades, with the last increase capped at $£ 9250$ in 2017. Statistically, the increase in fees from 1998 to 2017 appears dramatic; however, these increases correspond with sharp decreases in funding grants provided by the government that compensated HEIs that were running a per student deficit in many STEM fields. The decrease in grants, resulting from economic stagnation and austerity policies, placed a higher dependency on student tuitions as the principal revenue stream for most UK HEIs, impacting market viability for lower tabled institutions. In the late 1990 s, funding grants equated to $40 \%$ for most institutions revenue, while student tuition fees were approximately $25 \%$; however, current institutional finances attribute $6 \%$ (or less) to funding grants and 50\% (or more) to student tuitions (Hubble \& Bolton, 2018).

As a consequence of institutional economic shortfalls, HEIs have reduced budgetary allowances for bursaries, scholarships, and fee waivers, impacting lower incomed home students - reducing enrollment further in many mid to lower tabled HEIs. Before the pandemic, approximately $28 \%$ of all UK HEIs were running deficits, representing nearly a 5\% increase in institutional instability over the previous three years (HESA, 2020a). Financial constraints, a matured domestic market, and increased demands to modernise have resulted in an institutional shift towards aggressively recruiting international students to provide the financial resources required to remain competitive and, in some situations, financially solvent. International students are classified into two groups, EU students and international (all other non-EU students), each is subjugated to different program entry requirements and tuition fees. EU students are charged home student fees under the EU/EEA/Swiss educational provisions and are allowed 
equal immigration status to UK residents; while non-EU students are charged an international rate and must meet immigration requirements set by the UK government. Tuitions for international students vary depending on the program and institution, ranging from $£ 12,650$ (University of Bedfordshire) to an excess of $£ 31,230$ (University of Oxford) in general humanities programs and more than $£ 55,000$ (University of Cambridge) in the sciences. The difference in tuition fees between home and international students, $37 \%-500 \%$, incentifies institutions to aggressively recruit international students and expand capacities in high demand - high-profit programs.

At the institutional level, international students' increased engagement spurs program development and expansion of course availability; these changes are designed to accommodate and encourage further enrollment. The expansion of programs and modernisation of equipment has a knock-on effect for home students, as they are provided additional opportunities for program specialisation. Hegarty (2014) remarked that international students gravitate towards STEM programs, historically unpopular with home students. These programs are dependent on international students' tuition fees as the domestic market cannot support large scale program diversity across multiple institutions (Hegarty, 2014). To encourage increased home student engagement, the government scrapped the home student cap in 2015. While this policy reform increased applications and enrollment numbers, the 'surge' of home students still did not meet capacity demands for most institutions and solidified the financial needs of international students further.

\section{Brexit and EU Students}

Brexit has been a complicated and polarising political campaign that continues to raise profound questions about the long-term impact it will have on both the domestic and EU education market. While campaigned ideologies projected economic stability and self-governance, UK HEIs are experiencing significant instability and reduced capabilities to create institutional strategies due to inconsistent reports and government shifting policies. Under Brexit, EU students will lose their home student status and be classified as international students starting in the 2021/22 academic year, not only increasing incoming students tuition costs but dramatically impacting the entire application process. Current policies indicate that all EU nationals will need to apply for a tier 4 student visa before commencing their studies at a UK HEI, adding additional costs and time to the application process. EU students would have to provide financial evidence, showing they have access to financial resources that can cover their yearly fees. These fees would consist of tuition, educational supplies, food, additional expenses, and housing; Newcastle University (2019) estimates living costs at $£ 770$ plus tuition, while the University of Oxford recommends a budget of $£ 1175-1710$ /month (Oxford University, 2020). Therefore, new guidelines for EU students would require access to finances no less than $£ 9250$ to potentially over $£ 20520$ per year in addition to savings beyond the unspecified international fees for tuition for visa eligibility.

Independently securing loans and finances will become exponentially more difficult for the start of the 2021/22 academic year as EU students will need to follow tier 4 visa regulations regarding employment, allowing no more than an average of 20 hours per week during an academic term, conditions not applicable before Brexit. The limitation on working hours will impact those in a more financially precarious position, complicating abilities to maintain minimum earnings to cover living costs. These financial concerns are exasperated by the elimination of federal financial loans by the UK government to eligible EU nationals at the start of 2021/22 school year, essentially disqualifying large numbers of students from UK HEIs. According to surveys, the pending tuition increase and administrative difficulties related to tier 4 visas impact EU students' perception and attitude about furthering their studies in the UK. One study reported that up to $84 \%$ of prospective students would reconsider or seek alternative HEIs if tuition increases mirror the current international student tuition structure (Study.eu, 2020). A decrease of even a fraction of the EU student population result could have debilitating repercussions.

For the academic year, 2018/19 143025 EU students attended UK HEIs across all disciplines, representing 6\% of all students (HESA, 2020b) or $£ 1.16 \mathrm{~B}$ in yearly tuition revenue (HESA, 2020c). A $6 \%$ decline in annual tuition revenues would represent a $3 \%$ total revenue reduction in the majority of UK HEIs, shifting many into deficit. UK HEIs have aggressively sought to reduce anxiety with prospective students, holding educational trade shows, seminars, and question and answer sessions in many European cities pre-pandemic; yet, the continued uncertainty with government mitigates any strategic plans to counter growing dissolution among target groups. Fanciful musings, by the House of Commons' Education Committee, that uncertainty will not directly impact education attractiveness for EU students and a net gain is feasible immediately post-Brexit (House of Commons, 2017) - is simply political posturing. Short-term uncertainty will decrease the desirability of UK HEIs, as it poses risks and complications. Students will assess alternatives and their benefits against the perceived risks they may encounter in the UK. Short-term uncertainty will directly benefit competitors in Europe, reducing the UK HEI strategic position as the market leader. UK HEIs cannot abandon the EU market, with the proximity and large market size, institutions need to market and quell student apprehensiveness through brand awareness campaigns. Lower tabled 
institutions will again be disadvantaged as increased marketing costs will drive budget reductions in other areas of need, reducing market competitiveness and financial stability.

\section{UK Government's International Policies and International Students}

International students are crucial for the success and competitive capacity in the higher education market. As of the 2018/19 academic year, 342620 non-EU international students were registered in UK HEIs, representing approximately $14 \%$ of the total student body (HESA, 2020b). However, with variable tuition fees that are not subjugated to government-mandated tuition caps, non-EU students account for nearly $£ 6$ billion a year in tuition revenue representing or more than $30 \%$ of all HE course revenue (HESA, 2020c). As institutions realign recruitment strategies and increase emphasis is on individual brand awareness and recruitment campaigns. UK HEIs over the past decade have increased their marketing expenditure to penetrate high demand area: mainland China, India, Hong Kong, and Malaysia. Many institutions have little diversity when it comes to the international student population, with over-representation from a limited number of high demand countries (Hegarty, 2014). Mainland China alone accounted for 120385 registered students in UK HEIs, 35\% of the total non-EU students or more than $5 \%$ of all students (HESA, 2020b). With an increase of more than 30000 students since the 2014/2015 academic year (HESA, 2020b), institutions are becoming reliant on mainland China and a few other markets to drive financial growth; raising concern about over-exposure. If UK HEIs strategic growth relies on a limited source of represented countries, large-scale de-enrollment can occur without warning, decimating the institution's financial viability (Choudaha, 2017).

Government policies are incredibly efficient in promoting UK HEI attractability, creating the necessary channels to enter strategic markets and connecting with key officials; however, geopolitical disputes create nearly impenetrable barriers overnight that leave many institutions few avenues to operate. Current disagreements with China over the handling of Hong Kong, COVID-19, and other trade-related concerns have resulted in increased tensions and diplomatic sanctions from both sides. China has 'weaponised' students in the past, running media smear campaigns against New Zealand in the early 2000 s, resulting in a $25 \%$ decline in Chinese students the following semester. The control the Chinese government has over their students (and parents) is immense, and the consequence of the de-enrollment dramatically altered New Zealand HEIs, forcing the New Zealand government to create policies to appease the Chinese government. In early June 2020, China informed Australia that Chinese students would not be attending their universities as retaliation towards calls by the Australian government to open an international investigation into the COVID-19 outbreak. The threat sent shockwaves through the Australian educational sector, with concerns of dire economic ramifications if the threats are enforced. While Australian HEIs has a proximity advantage over UK institutions to China, UK HEIs are more exposed to a dramatic withdrawal from the Chinese market due to the larger student population size. More concerning, China has raised their disapproval towards the UK government with the current ban on Huawei technology and support for protestors in Hong Kong. These indirect sanctions may lead to a proposed reclassification of UK HEI certificates, potentially making them invalid for state government recruits. As tensions increase, UK HEIs become more vulnerable to student apprehension or direct government campaigns dissuading Chinese nationals from attending UK schools, weakening institutional reputation.

Institutionally, students are attracted by the university's reputation and the opportunities that a degree will provide them through culture-status (Meur et al., 2014). UK HEIs openly engage in branding, exposing potential recruits to their institutional message through social media or recruiters; however, parents are the major drivers in the application process and examine potential schools through a different lens (Falcone, 2017). As parents are the target of the Chinese government's 'recommendations', they are concerned about the viability of a degree in the long-term if domestic policies change. Parents also look at the cost-benefit of UK HEIs over alternatives, as the increasing tuition fees, rising exchange rates, and substantial living costs may decrease the degree's actual perceived value. Additionally, international competition for students has dramatically increased, with more non-traditional markets creating fully English programs to attract international students. These international markets offer incentives to potential students, lower tuition, closer proximity to their home, and better exchange rates; more students are being enticed away from the UK (Falcone, 2017). Countries that are historically exporters of students, China, India, and Korea, have also changed policies that make staying home more attractive to their students with increasing domestic HEI investment and lower tuition costs (Meur et al., 2014). As international competition continues to rise and geopolitical uncertain raises trepidation, UK HEIs marketing strategies increasingly burdening their profit line.

\section{Recommendations}

Issues concerning government policies, HEI economic stability, and international student dependence are complex 
and require a multifaceted strategy that is both institutional specific and industry inclusive. While government policies impact all UK HEIs, the level of exposure to dramatic enrollment declines is significantly linked to institutional rank and financial strength. The following suggestions are not meant to serve as solutions but instead starting points for both discussion and potential strategic adaptions.

\subsection{Home Tuition}

Home student tuitions rates rarely meet numerous institutions' financial threshold; however, aggressive lobbying for further increases to tuition fees or abolishing it altogether would be politically problematic. With current tuition rates in the UK considered one of the highest globally, political push back against further changes could create additional problems for HEIs that would deteriorate conditions that are already in dire straits. UK HEIs must aggressively lobby councils and government MPs to increase funding grants that have significantly diminished over the past decade. An industry-wide pressure on the government to reinstate previous levels of support will offset the gap between home tuition and institutional costs, principally to lower tabled HEIs that are currently in deficits. While lobbying for financial support is commonplace and not a new revelation; UK HEIs often promote agendas behind closed doors and generally avoid drumming up a public outcry through media campaigns. The absence of industry cohesiveness and public avoidance reduces the urgency of the situation and nullifies campaign effectiveness. If public universities begin to collapse under the financial strain of their operations, it will reduce the UK HEIs overall reputation, generating a knock-on effect to other institutions that are struggling to remain financially viable. Council hearings and occasional press release have not been adequate, UK HEIs must adopt an industry-wide response that articulates the need for increased grants, applying political pressure through marked media campaigns.

\subsection{Brexit}

With the reclassification of EU students occurring in the 2021/22 academic year, UK HEIs need to reassure potential students that studying in the UK is still advantageous. As international students are not prescribed set tuition fees, institutions can create regional specific models that offer tuition rates similar to UK home students but differ from other regions. Though rates will likely increase, smaller increments over a longer time frame will diminish the reclassification shock to potential students and still encourage students to enroll. The change in status additionally affects EU students from obtaining UK issued student loans, UK HEIs can offer similar payment plans that reduce the financial stress on EU students while fostering engagement. Financial support does not need to mimic the existing plan provided by the UK government, but provide a financial assistance alternative that meets the needs of prospective students. To limit exposure of debt delinquency or default through a loan system; HEIs can create joint programs with the UK and European financial institutions that offer student loans for studies in the UK, effectively distributing risk. Similar systems exist through financial-educational agreements and cooperatives in other countries like New Zealand, India, and the United States. This will not eliminate all concerns for students, but it could mitigate the hardships that many will financially face.

Immigration changes to EU students, requiring tier 4 student visas, are another government policy that will further complicate EU enrollment into UK HEIs. Similar to lobbying for additional funding grants, the entire educational industry needs to press for student freedom of movement agreement between the UK and the EU. Allowing students to travel on EU issued passports and attend a qualified institution without obtaining the separate student visa will quell fears. Though regulations about off-campus employment may create problems for some students, allowing students to attend HEIs without additional paperwork would diminish the potential mass exodus of EU students in 2021. UK institutions additionally can form stronger collaborative partnerships with EU educational bodies and institutions to offer joint programs. Though it would not provide the UK experience many students want, coupling a joint program with shorter summer programs could reduce immigration and financial concerns that students may have for the start of the 2021 academic year. Joint programs will not act as a substitute, but a compliment to UK HEIs through the opening (or expanding) of alternative revenue streams. Improved clarity on Brexit policies and freedom of movement agreements are crucial to stemming student outflow.

\subsection{International Student over Exposure}

UK HEIs are overexposed to international students because of the current educational climate that exists, hyper-competitive with a mature domestic market. The threat to many HEIs is not due to international students but the lack of diversity in their recruitment strategies and focusing primarily on limited groups. The reliance on China to drive institutional financial growth (or solvency) reduces HEI ability to adapt in stages of political turmoil or market shifts. Though institutions should continue to recruit Chinese students, more aggressive recruitment campaigns, need to occur in markets that have potential growth. South America (Columbia, Brazil), European nations not part of the EU (Russia), African nations (Nigeria, Kenya, Côte d'Ivoire), and south-east Asia (Vietnam, 
Thailand), all have growing markets that have limited representation currently in UK HEIs. Instead of the typical flat international rate being charged at UK institutions, an offering of variable tuition rates to drive interest may encourage additional enrollment in growth areas. Reduced tuition rates can draw the attention needed to promote growth in underperforming programs to untapped regions. Variable regional rates should not act to discourage existing markets like China and India from entry by dramatically increasing specific tuition fees, but to promote growth in other regions and slowly bringing rates to levels of overall conformity. Any increases in tuition rates to existing markets should be based on market principles, maximising engagement and reaching institutional capacity.

\subsection{Institutional Reforms}

Current deficits and financial instability are not purely connected to government policies but institutional design and structure. To attract students, institutions instilled a policy of program expansion that ultimately strained financial resources. Struggling institutions have under-enrollment and excessive institutional capacity that is taxing on their long-term stability. Industry-wide reconceptualisation needs to occur, gravitating towards specialist institutions from current generalist strategies. Lower tabled institutions need to create competitive advantages in specific programs and fields, diluting offerings negate institutional strength. Program cooperatives between similar structured institutions can better offer non-specialised programs to students while reducing the financial strain of maintaining similarily structured under-capacity classes. Cooperatives between institutions would offer the best resources to students and reduce institutional budget constraints. The issue with adapting cooperatives is that numerous institutions are concerned that sizeable shifts in programs or focus will negatively impact their brand image. However, if an institution is known for low enrollment and budget shortfalls, a shift in strategic position may improve long-term branding, while maintaining the status quo will damage it further.

While the majority of institutions have an online footprint, offering distance learning in some courses or programs; an expansion in this area may allow for the emphasis of core subjects on campus while allowing a diversity of programs to prospective students. The overhead operational costs to maintain an active online program is considerably less than onsight physical programs, reducing possible tuition fees for students and driving enrollment into a non-traditional HE course revenue streams. Institutions should not solely create new programs for their distance catalogue but offer existing programs through this alternative learning platform. The concept of expanding institutional online presence is not to throw every program possible into the mix but offer what the school presently has available and shifting lower revenue-generating classes to the distance learning catalogue to reduce expenditure while increasing student options.

\section{Conclusion}

UK HEIs face numerous difficulties in a growingly competitive domestic and international market. While government policies directly and indirectly connected to UK HEIs should promote the quality and advantages of a UK education; an increasing number of government initiatives have created immense financial stress and market apprehension. Tuition reforms that increase home rates while virtually eliminating funding grants have created a financial toll on domestic students and institutions. The UK government's strategy of shifting financial responsibility directly on the student and the institution, to offset economic shortfalls, has had a profound impact on those driving the economy. With increasing numbers of UK institutions running deficits, market stability is deteriorating, leading to an increased reliance on international student enrollment as a revenue stream. Unfortunately, institutional student diversity is limited to a few markets, leading to over-exposure.

This paper recommends that institutions re-evaluate their current strategy and create new policies that promote financial security and stability. To ensure external factors related to government policies act in UK HEIs' best interests, increased aggressive and potential public lobbying needs to occur; applying political pressure on MPs and other councils to act on current policies that reduce the attractiveness of a UK education. Institutions need to restructure policies that focus on program specialisation rather than generalisation, reducing programs that are under-capacity to optimise institutional expenditures. To increase alternative revenue streams, HEIs need to expand their distance education options to include more programs into this dedicated stream and create institutional cooperatives that can better serve student through resource/cost-sharing. As Brexit continues to create student apprehension, the UK educational industry needs to create financial support options to assist with EU students' funding to replace the UK education loans previously available. Joint programs with EU education providers can help reduce immigration concerns by offering the majority of the program off-campus with a limited number of summer programs to provide the UK experience. Finally, to ensure institutions are not over-exposed to a single group of students, focus on recruitment drives in under-represented high potential markets need to be emphasised. The offering of reduced international tuition rates to growth markets can increase interest, with the 
gradual increase in tuition fees as the market matures. Institutions should not abandon existing markets but offer incentives through reduced regional tuition fees, to create demand in other markets and improve enrollment diversity.

\section{References}

Choudaha, R. (2017). Assessing the effectiveness of international student recruitment. In J. B. Sandberg (Ed.), NAFSA's Guide to International Student Recruitment (3rd ed., pp. 245-252). Washington, DC: NAFSA: Association of International Education.

Falcone, S. (2017). International student recruitment: trends and challenges. Journal of International Students, 7(2), 246-256. https://doi.org/10.32674/jis.v7i2.379

Gaskell, S. (2015). Quality, equity, sustainability: The future of higher education regulation. Report of the UK Regulation Task and Finish Group. London: Universities UK.

Hegarty, N. (2014). Where are we now - the presence and importance of international students to universities in the United States. Journal of International Students, 4(3), 223-235. https://doi.org/10.32674/jis.v4i3.462

HESA. (2020a). Consolidated statement of comprehensive income and expenditure by HE provider and academic year 2015/16 to 2018/19. HESA.

HESA. (2020b). HE student enrollment by domicile and region of HE provider 2014/15 to 2018/19. HESA.

HESA. (2020c). Tuition fees and education contracts analysed by domicile, mode, level and source 2016/17 to 2018/19. HESA.

House of Commons. (2017). Exiting the EU: challenges and opportunities in higher education. House of Commons Education Committee, Ninth report of session 2016-2017.

Hubble, S. \& Bolton, P. (2018). Higher education tuition fees in England. House of Commons Library Briefing Paper, number 8151.

Meur, D., Chong, F. N., \& Nisbet, A. (2014). The growing importance and reliance on international students in New Zealand: a looming crisis. Joint AARE-NZARE 2014 Conference, Brisbane 2014 (pp. 1-14).

Newcastle University. (2019). Living costs. Newcastle University. Retrieved from https://www.ncl.ac.uk/study/student-life/cost/

Oxford University. (2020). Living costs for 2021-entry. Oxford University. Retrieved from https://www.ox.ac.uk/admissions/undergraduate/fees-and-funding/living-costs

Rios, C. (2019). Challenges to the internationalisation of United Kingdom universities. International Research and Review, Journal of Phi Beta Delta Honor Society for International Scholars, 8(2), 16-32.

Sa, CM, \& Sabzalieva, E. (2017). The politics of the great brain race: public policy and international student recruitment in Australia, Canada, England and the USA. Higher Education, 75, 231-253. https://doi.org/10.1007/s10734-017-0133-1

Slaughter, S., \& Cantwell, B. (2012). Transatlantic moves to the market: The United States and the European Union. Higher Education, 63, 583-606. https://doi.org/10.1007/s10734-011-9460-9

Study.eu. (2020, July 1). UK universities might lose $84 \%$ of EU students at higher fees - survey. study.eu. Retrieved from https://www.study.eu/press/uk-universities-might-lose-84-of-eu-students-at-higher-feessurvey

\section{Copyrights}

Copyright for this article is retained by the author(s), with first publication rights granted to the journal.

This is an open-access article distributed under the terms and conditions of the Creative Commons Attribution license (http://creativecommons.org/licenses/by/4.0/). 